plantation. Since all of the kidneys discarded in this study perfused well with the initial perfusate solution, continuous perfusion probably provides a more satisfactory method of screening cadaveric kidneys before transplantation.

Continuous perfusion of human cadaveric kidneys has been reported from San Francisco (Belzer and Kountz, 1970), Los Angeles (Moore et al., 1971), Richmond (Sterling et al., 1971), New York (McCabe and Fitzpatrick, 1972), Cleveland (Kiser et al., 1971), and Gothenburg (Claes et al., 1972). In some centres the perfusion machine is mobile, being taken to both donor and recipient hospitals with the kidney; in others, kidneys are brought to a central perfusion laboratory in ice. Scott et al. (1971) have shown that cold ischaemia is better tolerated in dogs before, rather than after, a period of continuous perfusion, and hence concluded that kidneys could be removed at local hospitals and transported to the preservation laboratory in ice, but they did not recommend transporting stored kidneys in ice after continuous perfusion. In Scandinavia, G. Claes (personal communication, 1972) has preferred to take the perfusion machine to the recipient if possible. However, Kiser et al. (1971) concluded that with human kidneys postperfusion cold ischaemia of up to $3 \frac{3}{4}$ hours did not affect the function of the kidney adversely. The results of this study appear to confirm this conclusion, although it seems that if the combined cold ischaemia times before and after perfusion exceed 10 hours onset of renal function is likely to be delayed.

The introduction of this preservation system has extended greatly the period during which cadaveric kidneys may be stored. Immediate function has been obtained after preservation for up to 36 hours, and kidneys have been discarded which previously would have been transplanted probably with poor subsequent function. It is expected that the results of cadaveric kidney transplantation should be significantly improved by routine preservation by continuous perfusion, and the assessment of viability before transplantation to well-matched recipients.

We wish to thank the staff of the transplantation units of the following hospitals for kindly providing information on the function of the kidneys: Queen Elizabeth Hospital, Birmingham; Jervis Street Hospital, Dublin; Western General Hospital, Edinburgh; Sahl- grenska Sjukhuset, Gothenburg; Academisch Ziekenhuis, Leiden; Charing Cross, Guy's, Hammersmith, The London, Royal Free, and the Westminster Hospitals, London; and the Royal Victoria Infirmary, Newcastle.

We also wish to thank the transplant immunology unit at the London Hospital Medical College, and the National Organ Matching Service, Bristol, for their help and co-operation.

Financial support was provided by the Boards of Governors of St. Bartholomew's Hospital and St. Peter's Hospitals, and by the St. Peter's Research Trust and the Institute of Urology.

\section{References}

Barnes, A. D., Dawson-Edwards, P., Powis, S. J. A., and Thomas, D. R. (1972). Lancet, 1, 199.

Belzer, F. O., and Kountz, S. L. (1970). Annals of Surgery, 172, 394

Belzer, F. O., Reed, T. W., Pryor, J. P., Kountz, S. L., and Dunphy, J. E. (1970). Surgery, Gynecology and Obstetrics, 130, 467.

British Medical fournal, 1972, 3, 251.

Brunius, U., Bergentz, S. E., Ekman, H., Gelin, L. E., and Westberg, G. (1968). Scandinavian fournal of Urology and Nephrology, 2, 15.

Claes, G., Aurell, M., and Brunius, U. (1970). Nordisk Medicin, 84, 923.

Claes, G., and Blohme, I. (1971). Nordisk Medicin, 86, 881.

Claes, G., Blohme, I., and Gelin, L. E. (1971). Proceedings of the European Dialysis and Transplant Association, 8, 307.

Claes, G., Aurell, M., and Blohme, I. (1972). Proceedings of the European Dialysis and Transplant Association. 9,484

Collins, G. M., Bravo-Sugarman, M., and Terasaki, P. I. (1969). Lancet, 2, 1219.

Cooperman, A. M., Woods, J. E., Holley, K. E., and McIlrath, D. C. (1971). Mayo Clinic Proceedings, 46, 193.

Dausset, J., and Hors, J. (1972). Nature New Biology, 238, 150.

Festenstein, H. et al. (1971). Lancet, 2, 225.

Gelin, L. E. et al. (1967). Fournal of Cardiovascular Surgery (special issue) 8th Congress of the International Cardiovascular Society, Vienna, September 1967, p. 78.

Horsburgh, T. (1973). Nature. In press.

Hulme, B., Snell, M. E., Kenyon, J. R., Owen, K., and Peart, W. S. (1972). British Medical fournal, 4, 139.

Kiser, W. S., Magnusson, M. O., McLaughlin, T. C., Hewitt, C. B., and Straffon, R. A. (1971). Fournal of Urology, 105, 779.

McCabe, R. E., and Fitzpatrick, H. F. (1972). Fournal of the American Medical Association, 219, 1056.

Milliez, P. et al. (1972). Lancet, 2, 887.

Moore, T. C., Berne, T. V., Martin, D. C., and English, T. S. (1971). Trans-

plantation, 12, 526.
Oliver, R. T. D., Sachs, J. A., and Festenstein, H. Pegrum G. D., and Moorhead, J. F., (1972). Lancet, 2, 1381 .

Scott, D. F., Stephens, F. O., Keaveny, T. V., Kountz, S. L., and Belzer, F. O. (1971). Transplantation, 11, 90

Sells, R. A., and Pena, J. R. (1970). Lancet, 2, 539.

Sterling, W. A., Pierce, J. C., Hutcher, N. E., Lee, H. M., and Hume, D. M. (1971). Surgical Forum, 22, 229.

\title{
Assessment of Acid-base Disturbances Employing a Desk-top Computer
}

\author{
A. W. GROGONO
}

British Medical fournal, 1973, 1, 381-386

\section{Summary}

Patients in an intensive care unit have had their acid-base status satisfactorily assessed for some months using a desktop computer. Any department able to juxtapose an Astrup apparatus and a programmable calculator will find the method convenient to use.

Royal Free Hospital, London NW3 2X]

A. W. GROGONO, F.F.A. R.C.s., Consultant Anaesthetist

\section{Introduction}

Acid-base disturbances are commonly assessed using the Astrup interpolation technique (Astrup, 1956; Siggaard Andersen et al., 1960; Siggaard Andersen and Engel, 1960; Mellemgaard and Astrup, 1960; Siggaard Andersen, 1962). Three $\mathrm{pH}$ readings are required for a complete determination of the patient's acid-base state; the pH of the original sample is measured as well as the $\mathrm{pH}$ of the blood when tonometered with two different mixtures of carbon dioxide and oxygen. The buffer line thus established is plotted on a nomogram from which may be read the patient's $\mathrm{PCO}_{2}$, standard bicarbonate, base excess, and buffer base. The technique has several advantages. Only a single electrode needs to be maintained, calibrated, and understood; use of the technique 


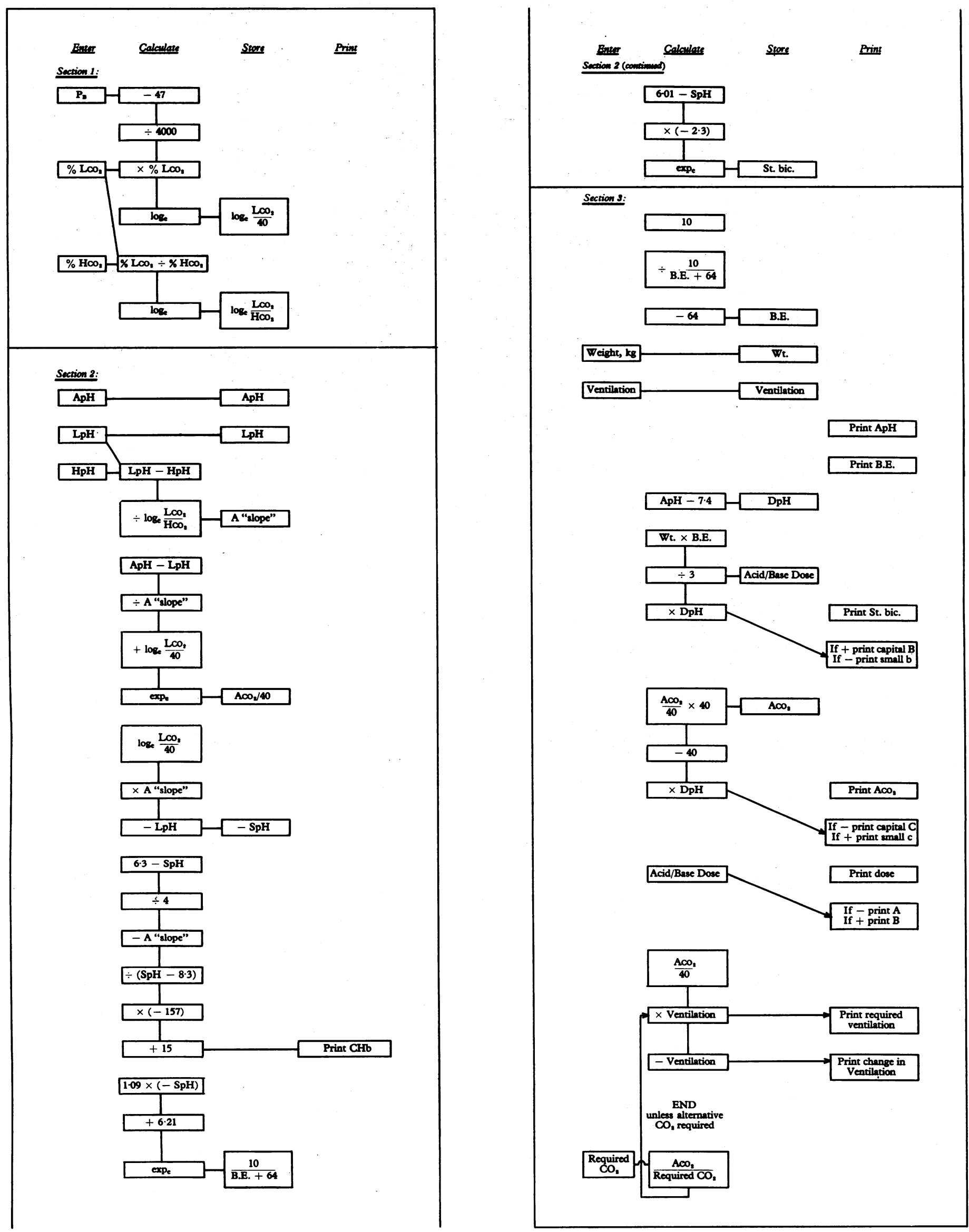


affords considerable insight into this confusing area of clinical management; the method allows correction for hypoxia to be applied; and it provides a value for the haemoglobin, which can be used as confirmation that the results are at least compatible with the patient. Bizarre haemoglobin values indicate that the electrode calibration and equilibration should be repeated; however, experience suggests that these two features are commonly neglected. The correction for anoxia is seldom applied because its influence on clinical management is usually negligible, and the haemoglobin check is frequently omitted. Consequently it is all too common to see an "impossible" slope not compatible with any haemoglobin value, and the necessity of repeating the calibration and equilibration remains unrecognized.

Computer programs have been prepared for the calculation of results by large computers (Jalowayski et al., 1968; Vallbona et al., 1971) but they are not readily adapted for use where there is limitation on storage capacity or program length and they do not offer a simple method of calculating the haemoglobin as a reliability check. Programs for use with desk-top computers have also been described. Hardt (1972) described a program for use with the Olivetti Programma 101. As written, however, it is applicable only in laboratories using identical standard gas mixtures, the equation selected to derive base excess depends on the position of the buffer line, and the reliability check used will allow results to be printed even though the buffer line accepted may represent haemoglobin values of less than 0 to more than $40 \mathrm{~g} / 100 \mathrm{ml}$.

Hewlett Packard described a program devised by Thomson and Medarts for use with the model 10 series calculator. This program is more versatile and may be used with any Pco, values. However, the equation used for base excess yields minor discrepancies between computed results and the Siggaard Andersen nomogram and there is no reliability check or haemoglobin result.

This paper reports a program for equipment with limited storage capacity and program length. A satisfactory expression for haemogloblin is presented as well as a new approximation for base excess. The program was developed primarily for use with an Olivetti Programma 101, but since it is also suitable for use with other desk-top computers the equations and flow diagram are presented here as well.

\section{Method}

The design and arrangement of the calculations (see figs. 1 and 2) minimizes storage requirements and allows the sequence to be broken into three sections. In the section 1 of the program (fig. 1) the operator enters the barometric pressure and percentage concentrations of $\mathrm{CO}_{2}$ in the standard gases used for equilibration $\left(\% \mathrm{LCO}_{2}, \% \mathrm{HCO}_{2}\right)$. (A key to the abbreviations is given in the Appendix.). This information is used to generate two constants $\left(\log _{e}\left(\operatorname{LCO}_{2} / 40\right)\right.$ and $\log _{c}$ $\left.\left(\mathrm{LCO}_{2} / \mathrm{HCO}_{2}\right)\right)$, which are stored and used for all analyses to be performed provided that the barometric pressure and standard gases remain unchanged.

In section 2 the operator enters the $\mathrm{ApH}$ and the $\mathrm{pH}$ of the blood exposed to the equilibration gases ( $\mathrm{LpH}, \mathrm{HpH})$. In conjunction with the two constants obtained in section 1 a ratio is calculated (A "slope") equivalent to the slope of the buffer line on a Siggaard Andersen nomogram followed by the the patient's $\mathrm{PCO}_{2}\left(\mathrm{AcO}_{2}\right)$ and the $\mathrm{pH}$ at a $\mathrm{PCO}_{2}$ of $40 \mathrm{~mm} \mathrm{Hg}$ $(\mathrm{SpH}) ; \mathrm{SpH}$ is used to calculate the standard bicarbonate and base excess and is used with A "slope" to calculate the patient's haemoglobin ( $\mathrm{CHb}$ ). This haemoglobin is the only value printed in section 2 , and if it is acceptable the operator proceeds to the next section.

In section 3 the operator enters the patient's weight in kilogrammes followed by the ventilation in the most convenient form-for example, minute volume, tidal volume, or even respiratory rate. Next the $\mathrm{pH}$, base excess, standard bicarbonate, and $\mathrm{PCO}_{2}$ are printed. The direction of the metabolic and respiratory changes is compared with the direction of the overall $\mathrm{pH}$ change. A change in the same direction is regarded as primary, whereas a change in the opposite direction is regarded as compensatory; this is indicated by appropriate symbols printed beside the value for standard bicarbonate and $\mathrm{PCO}_{2}$. The end of section 3 deals with therapy. The dose in milliequivalents is printed with $A$ or $B$ to indicate acid or base to be given. Under this is printed the required ventilation followed by the alteration necessary to achieve it. In gross respiratory disturbance it is possible at this point to enter an intermediate $\mathrm{PCO}_{2}$ for a more modest change in the ventilation to be calculated.

The example of gross respiratory acidosis shown in fig. 2 illustrates the use of the alternative $\mathrm{CO}_{2}$ value at the end.

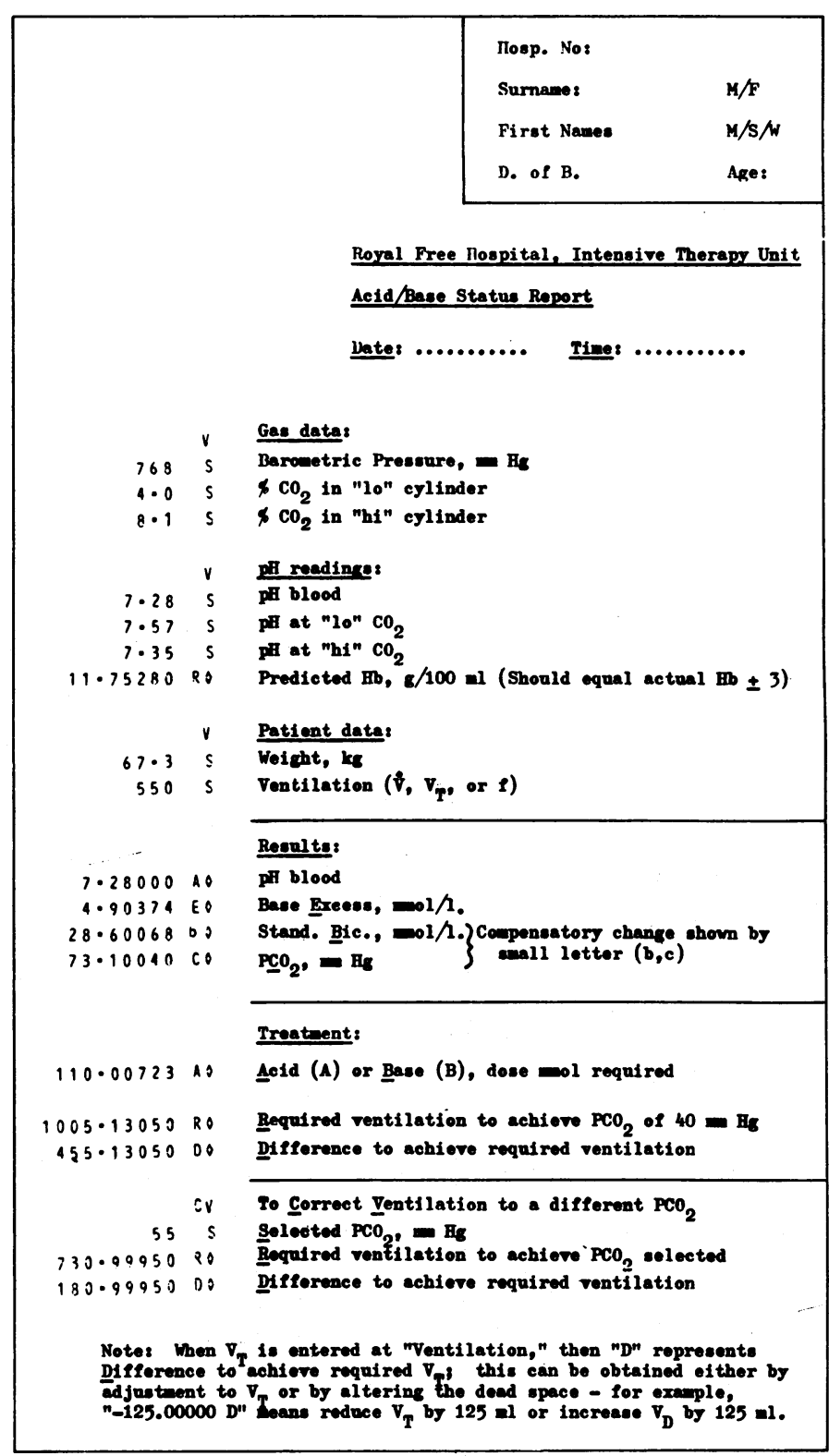

pIG. 2-Completed report on patient with gross respiratory acidosis. Computer print-out values are shown on the left.

\section{Derivation of Equations}

To suit programmable calculators with no built-in logarithmic functions the program is arranged so that logarithms may be conveniently derived using a modified Maclaurin's series 
and the exponents using a factorized version of a Maclaurin's series. Accordingly, natural logarithms and exponents (base "e") are employed, and to minimize delay and truncation error equations have been chosen so that numerical values are in the region of \pm 2.0 . Equations 1-5 (table I) assume a rectilinear relationship between $\log \mathrm{PCO}_{2}$ and pH and allow calculation of A "slope," $\mathrm{PCO}_{2}$, and $\mathrm{SpH}$.

TABLE I-List of Equations Used
(1) $\log _{\mathrm{e}} \frac{\mathrm{LCO}}{40}$
(2) $\log _{\mathrm{e}} \frac{\mathrm{LCO}_{2}}{\mathrm{HCO}_{2}}$
$=\log _{e}\left(\frac{\% \mathrm{LCO}_{2}+(\mathrm{PB}-47)}{4,000}\right)$
(3) A "slope"
$=\log _{\mathrm{e}}\left(\frac{\% \mathrm{LCO}_{2}}{\% \mathrm{HCO}_{3}}\right)$
$=\frac{\mathrm{LpH}-\mathrm{HpH}}{\log _{\mathrm{e}}\left(\frac{\mathrm{LCO}}{\mathrm{HCO}_{3}}\right)}$
(4) $\frac{\mathrm{AcO}_{2}}{40}$
$=\operatorname{expe}_{e}\left(\frac{\mathrm{ApH}-\mathrm{LpH}}{\mathrm{A} \text { "slope" }}+\log _{\mathrm{e}} \frac{\mathrm{LCO}_{2}}{40^{2}}\right)$
(5) $\mathrm{SpH}$
(6) N "slope"
$=\mathrm{LpH}-\left(\log _{\mathrm{e}} \frac{\mathrm{LCO}_{2}}{40}\right) \times A$ "slope"
(7) $\mathrm{CHb}$
(8) $\frac{10}{\text { B.E. }+64}$
$=\frac{6.3-\mathrm{SpH}}{4}$
(9) B.E.
(10) St. bic.
(11) Dose
(12) Required ventilation
(13) $\mathrm{DpH}$
(14) Dose $\times \mathrm{DpH}\left\{\begin{array}{l}\text { Positive } \\ \text { Negative }\end{array}\right.$
$=15-\left(\frac{\text { A "slope" }-\mathrm{N} \text { "slope" }}{\mathrm{SpH}-8 \cdot 3}\right) \times 157$
$=\operatorname{expe}_{\mathrm{e}}(6.21-1.09 \times \mathrm{SpH})$
$=10 \div\left(\frac{10}{\text { B.E. }+64}\right)-64$
$=\exp _{\mathbf{e}}(2.3 \times(\mathrm{SpH}-6.01))$
$=\frac{\text { Wt } \times \text { B.E. }}{3}\left\{\begin{array}{l}\text { Positive }=\text { give acid } \\ \text { Negative }=\text { give base }\end{array}\right.$
$=$ Ventilation $\times \frac{\mathrm{AcO}_{2}}{40}$
$=\mathrm{ApH}-7 \cdot 4$
$=$ Metabolic disturbance is primary
$=$ Metabolic disturbance is compensatory
(15) $\left(\frac{\mathrm{ACO}_{2}}{40}-1\right) \times \mathrm{DpH}\left\{\begin{array}{l}\text { Negative }=\text { Respiratory disturbance is primary } \\ \text { Positive }=\text { Respiratory disturbance is compensatory }\end{array}\right.$

On the Siggard Anderson nomogram any buffer line has a corresponding haemoglobin value. An equation to represent this relationship was established by plotting four buffer lines on the nomogram (table II). Lines 1 and 3 correspond to a haemoglobin value of $15 \mathrm{~g} / 100 \mathrm{ml}$, one at a base excess of $+15 \mathrm{mEq} / \mathrm{l}$. and the other at $-15 \mathrm{mEq} / \mathrm{l}$. Through the $\mathrm{SpH}$ for these two lines lines 2 and 4 were constructed for a haemoglobin of $7.5 \mathrm{~g} / 100 \mathrm{ml}$. By using values from the graph in equation 3 A "slope" was computed for all four lines; the values obtained for lines 1 and 3 were used to derive a linear regression equation so that the slope for a normal haemoglobin (N "slope") could be calculated for $\mathrm{SpH}$ :

$$
\mathrm{N} \text { "slope" }=\frac{6 \cdot 312-\mathrm{SpH}}{3.951}
$$

Equation 6 represents a satisfactory approximation of this relationship. Lines 2 and 4 show the change in slope (D "slope") caused by a fall in haemoglobin to $7.5 \mathrm{~g} / 100 \mathrm{ml}$, and a linear regression equation was obtained relating $\mathbf{D}$ "Slop" to SpH: D "slope" $=(\mathrm{SpH}-8.278) \times 0.0484$.

TABLE II-Values Used to Derive Equations for Predicting Haemoglobin. Haemoglobin and $\mathrm{pH}$ Values were Obtained from Buffer Lines on a Siggaard Andersen Nomogram and the Other Values were Calculated in Accordance with the Text

\begin{tabular}{|c|c|c|c|c|c|}
\hline \multicolumn{2}{|c|}{ Buffer line No.: } & 1 & 2 & 3 & 4 \\
\hline $\begin{array}{l}\text { Haemoglob } \\
\text { pH at }\left\{\begin{array}{l}\text { PC } \\
\text { PC } \\
\text { PC }\end{array}\right. \\
\text { A "slope" } \\
\text { N "slope" } \\
\text { D "slope" }\end{array}$ & 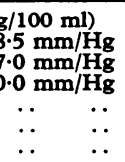 & $\begin{array}{c}15 \cdot 0 \\
7.222 \\
7.075 \\
7.150 \\
-0.212 \\
-0.212 \\
0.0\end{array}$ & $\begin{array}{r}7.5 \\
7.241 \\
7.056 \\
7.150 \\
-0.267 \\
-0.212 \\
-0.055\end{array}$ & $\begin{array}{c}15 \cdot 0 \\
7.705 \\
7.480 \\
7.595 \\
-0.325 \\
-0.325 \\
0.0\end{array}$ & $\begin{array}{l}7.5 \\
7.716 \\
7.468 \\
7.595 \\
-0.358 \\
-0.325 \\
-0.033\end{array}$ \\
\hline
\end{tabular}

The ratio between the change in slope actually found and D "slope" represents the effect of the fall in haemoglobin relative to a fall in haemoglobin to $7.5 \mathrm{~g} / 100 \mathrm{ml}$ :

$$
\begin{gathered}
\frac{\mathrm{A} \text { "slope" }-\mathrm{N} \text { "slope" }}{(\mathrm{SpH}-8.278) \times 0.0484}=\frac{15-\mathrm{CHb}}{15-7.5} \\
\text { that is, } \mathrm{CHb}=15-7.5 \frac{\mathrm{A} \text { "slope" }-\mathrm{N} \text { "slope" }}{(\mathrm{SpH} 8.278) \times 0.0484}
\end{gathered}
$$

Therefore

$$
\mathrm{CHb}=15-154 \cdot 8\left(\frac{\mathrm{A} \text { "slope" }-\left(\frac{6.312-\mathrm{SpH}}{3.951}\right)}{\mathrm{SpH}-8.278}\right)
$$

Equation 7 is an approximation of this relationship, and its validity is assessed and discussed separately below.

An equation to represent adequately the relation between base excess and $\mathrm{SpH}$ was found to be of the form

$$
\log _{e}\left(K_{1}+\text { B.E. }\right)=\left(K_{2} \times S p H\right)+K_{3}
$$

Numerical values for these constants were found by inserting in this equation values for B.E. and $\mathrm{SpH}$ obtained from a Siggaard Andersen nomogram; the lines chosen were for a haemoglobin of $15.0 \mathrm{~g} / 100 \mathrm{ml}$ with base excess values of $+20,0$, and $-20 \mathrm{mmol} / \mathrm{l}$, and they provided three simultaneous equations:

$$
\begin{aligned}
& \log _{e}\left(K_{1}+20\right)=\left(K_{2} \times 7.650\right)+K_{3} \\
& \log _{e}\left(K_{1}+0\right)=\left(K_{2} \times 7.400\right)+K_{3} \\
& \log _{e}\left(K_{1}-20\right)=\left(K_{2} \times 7.055\right)+K_{3}
\end{aligned}
$$

Solution of these equations yields

$$
\begin{gathered}
\log _{e}(63.7+\text { B.E. })=(1.09 \times \mathrm{SpH})-3.91 \\
\text { that is, B.E. }=\exp _{e}(1.09 \mathrm{SpH}-3.91)-63.7
\end{gathered}
$$

The variation of this relationship used (equations 8 and 9) enables the value computed to be in a range more suitable for the exponential calculation; it is also different enough from the other values computed by this exponential routine to be used as the basis of a test to ensure that this section of the program is complete.

Equation 10 allows the standard bicarbonate to be calculated from $\mathrm{SpH}$. Equation 11 calculates the base or acid requirements and equation 12 indicates the ventilation required to return the $\mathrm{PCO}_{2}$ to normal.

Equations 13, 14, and 15 were developed for use in this program as a means of performing the Boolean logic associated with determining whether a disturbance is primary or compensatory. The basis for these equations is that a disturbance will be regarded as compensatory when the overall $\mathrm{pH}$ change is in the opposite direction.

\section{Program for Olivetti Programma 101}

The program is compiled on three separate cards (fig. 3) and is designed to run with the decimal wheel set at 5 . Every card uses "V" as the key to initiate the program and the construction of the program is such that intermediate values are not erased when cards are changed. Section 1 calculates the logarithms (equations 1 and 2). The logarithms generated are negative values, and these are used as the basis for the test to determine that the computation of the logarithms is complete. Section 2 employs every instruction available and shows jump instructions around three stores used for numeri- 


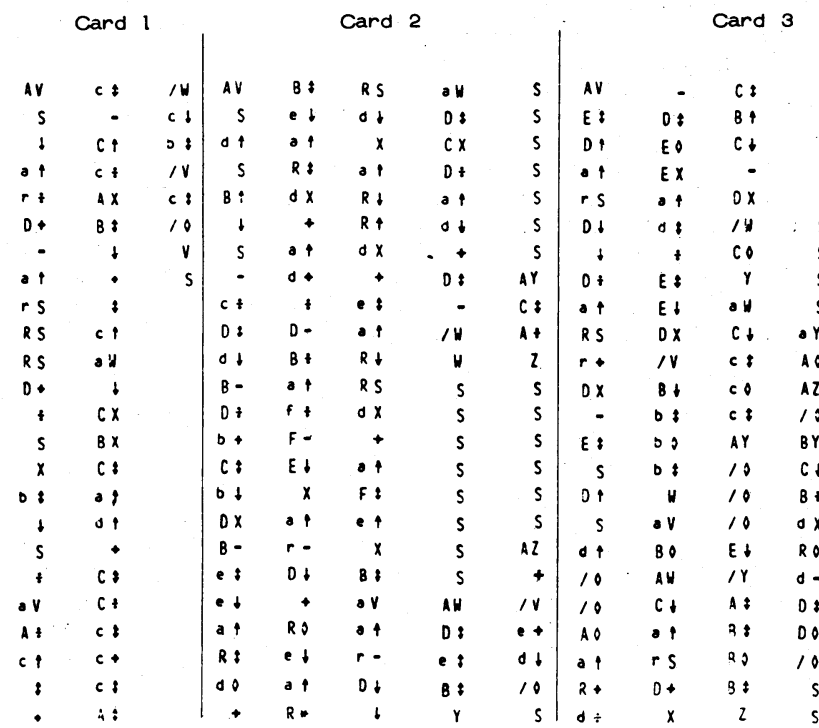

FIG. 3-Program for Olivetti Programma 101.

cal values. All computations are first completed up to the point where the exponent must be calculated, as the one exponent subroutine is used for all three values (B.E., St. bic., and $\left.\mathrm{P}_{2}\right)$. On this occasion the test that all computation is complete is based on the fact that one value, the log $(10 /($ B.E. + 64)), is significantly negative. At the end of this section all required numerical values are placed in appropriate locations to prevent erasure as the final card is inserted. The final card calculates and prints the results followed by the appropriate therapy. The Boolean logic associated with the identification of compensatory changes, and with the choice between giving acid or base, is carried out in terms of " + " and "-,", and the program is arranged for the result of these computations to be represented by a suitable letter beside the relevant numerical value (fig. 2 ).

\section{Evaluation of Accuracy}

As the Siggaard Andersen nomogram was used as the basis for deriving the equations used in this program a comparison was made of the results obtained by the two methods. Assuming a normal atmospheric pressure and standard gases of $4.0 \%$ and $8.0 \% \mathrm{CO}_{2}, \mathrm{LpH}$, and $\mathrm{HpH}$ values were obtained from the nomogram at $\mathrm{LCO}_{2} 28.5 \mathrm{~mm} \mathrm{Hg}$ and $\mathrm{HCO}_{2} 57.0 \mathrm{~mm}$ Hg. Twenty sets of readings were used, spread throughout the clinical range, and the results obtained with the two systems agreed well with each other, as shown by the coefficients of regression $(a, b)$ and correlation (r) in table III.

TABLE III-Evaluation of Accuracy. Regression and Correlation Coefficients for Values obtained by Nomogram and by Computer

\begin{tabular}{|c|c|c|c|c|c|c|c|}
\hline & & & & & \multicolumn{2}{|c|}{$\begin{array}{l}\text { Regression Coefficients for } \\
\text { Equation } \mathbf{C}=\mathrm{aN}+\mathrm{b}\end{array}$} & \multirow{2}{*}{$\begin{array}{c}\text { Correlation } \\
\text { Coefficient } \\
\mathbf{r}\end{array}$} \\
\hline & & & & & $\mathbf{a}$ & b & \\
\hline $\begin{array}{l}\text { Hb. . } \\
\text { B.E. } \\
\text { St. bic. } \\
\text { Aco, }\end{array}$ & $\begin{array}{l}\ddot{ } \\
\ddot{*}\end{array}$ & $\begin{array}{l}\ldots \\
\cdots \\
\cdots\end{array}$ & $\begin{array}{l}\ldots \\
\cdots \\
\ldots\end{array}$ & $\begin{array}{l}\ldots \\
\cdots \\
\cdots\end{array}$ & $\begin{array}{l}1.001 \\
1.029 \\
0.953 \\
0.996\end{array}$ & $\begin{array}{r}0.183 \\
-0.177 \\
1.122 \\
0.149\end{array}$ & $\left\{\begin{array}{l}\text { In excess } \\
\text { of } 0.999\end{array}\right.$ \\
\hline
\end{tabular}

$C=$ Computed value. $\mathrm{N}=$ Nomogram value.

\section{Discussion}

The management of acid-base disturbances is one of the few fields in medical practice where complex arithmetic in- fluences treatment; if the steady introduction of desk-top programmable calculators is to influence patient management, then it will be in just such a field. It was with this in mind that this program was developed and tested.

The program has run smoothly using the Olivetti 101, and staff performing Astrup estimations compute the results in preference to employing the nomogram. The automatic printing of a computed haemoglobin has proved a powerful incentive for accurate electrode calibration and careful $\mathrm{pH}$ measurement. The calculation of this haemoglobin value employs linear regression equations derived from two points; this is justified by the satisfactory correlation with the nomogram.

The decision reached by the program on whether a change is compensatory or primary is frequently superfluous, as staff are usually experienced enough to manage patients without this information; however, they do find it convenient to have the print of A or B to confirm whether acid or base is required. Tidal volume is generally chosen for insertion in the data when a patient is on a ventilator, as this allows the alteration indicated to be interpreted either as an alteration in the tidal volume or as an alteration in the external dead space.

Much of the advantage derives from having the computer adjacent to the $\mathrm{pH}$ measuring equipment. As results are obtained they can be typed into the computer, thus eliminating the ubiquitous scraps of unidentifiable paper and also reducing transcription errors. As the computer takes up to about 45 seconds to perform the calculation an experienced operator takes advantage of this time to proceed with other measurements or by cleaning the equipment. The data on which the calculation is based remain on the report paper and are therefore available for a clinician to check if he wishes. The choice of input format suits the operator as the information becomes available in the order required, the ApH being normally measured while the other samples are tonometered.

$\log _{e}\left(\mathrm{LCO}_{2} / 40\right)$ was chosen as one of the constants derived and stored in section 1 for several reasons; it is a small enough value to allow the logarithm to be generated by the modified Maclaurin's series without undue delay or appreciable truncation error, its logarithm is used when calculating the $\mathrm{pH}$ at a $\mathrm{PCO}_{2}$ of $40 \mathrm{~mm} \mathrm{Hg}(\mathrm{SpH})$, and the expression derived for the patient's $\mathrm{PCO}_{2}$ is in the form of $\mathrm{ACO}_{2} / 40$, which is useful as a correction factor when deriving an approximate value for the new ventilation from the previous ventilation.

\section{Appendix}

\section{ABBREVIATIONS USED}

$\log _{e} \log _{10}=$ Logarithm to base "e" or base "10."

$\mathrm{PB}=$ Barometric pressure in $\mathrm{mm} \mathbf{H g}$.

$\mathrm{LCO}_{2}=$ Partial pressure of carbon dioxide in "low pressure" equilibration gas in $\mathbf{m m} \mathbf{~} \mathbf{g}$.

$\mathrm{HCO}_{2}=$ Partial pressure of carbon dioxide in "high pressure" equilibration gas in $\mathrm{mm} \mathbf{H g}$.

$\mathrm{ACO}_{2}=$ Actual partial pressure of carbon dioxide in patient's blood in $\mathbf{m m ~} \mathbf{~ g g}$.

$\mathrm{LpH}=\mathrm{pH}$ of blood equilibrated with $\mathrm{LCO}_{2}$.

$\mathrm{HpH}=\mathrm{pH}$ of blood equilibrated with $\mathrm{HCO}_{2}$.

$\mathrm{ApH}=$ Actual $\mathrm{pH}$ of blood.

$\mathrm{SpH}=\mathrm{pH}$ of blood at $\mathrm{PCO}_{2}$ of $40 \mathrm{~mm} \mathrm{Hg}$.

A "slope" = Ratio between $\mathrm{pH}$ range and $\log _{\mathrm{e}} \mathrm{PCO}_{2}$ range. Comparable to the slope of a Siggaard Andersen nomogram.

N "slope" = Normal slope calculated from $\mathrm{SpH}$ for a haemoglobin of $15 \mathrm{~g} / 100 \mathrm{ml}$.

D "slope"=Change in slope caused by a fall in haemoglobin to $7 \cdot 5 \mathrm{~g} / 100 \mathrm{ml}$.

$\mathrm{CHb}=$ Calculated haemoglobin in $\mathrm{g} / 100 \mathrm{ml}$ which should be approximately equal to the actual haemoglobin.

St. bic. $=$ Standard bicarbonate (bicarbonate ion concentration at $\mathrm{PCO}_{2}$ of $40 \mathrm{~mm} \mathrm{Hg}$ ) in $\mathrm{mmol} / 1$.

B.E.=Base excess in $\mathrm{mmol} / 1$. 
$\exp _{e}, \exp _{10}=$ Exponential value to base " $e$ " or base "10" (=antilogarithm).

Dose $=$ Calculated requirement of acid or base in mmol.

Required ventilation $=$ Ventilation calculated to correct $\mathbf{P C O}_{2}$ $\mathrm{DpH}=$ Difference between $\mathbf{7 \cdot 4}$ and $\mathrm{ApH}$.

$f=$ Frequency.

\section{Addendum}

This program has recently been adapted for use with an Olivetti Programma 602. Copies of the program are available from the author.

\section{References}

Astrup, P. (1956). Scandinavian fournal of Clinical and Laboratory Investigation, $8,33$.

Hardt, J. (1972). Clinical Chemistry, 18, 658

Jalowayski, A., Lauterbach, R., Smith, B. E., and Modell, J. H. (1968) fournal of Laboratory and Clinical Medicine, 71, 328.

Mellemgaard, K., and Astrup, P. (1960). Scandinavian fournal of Clinical and Laboratory Investigation, 12, 187.

Siggaard Anderson, O. (1962). Scandinavian Fournal of Clinical and Laboratory Investigation, 14, 598 .

Siggaard Anderson, O., and Engal, K. (1960). Scandinavian fournal of Clinical and Laboratory Investigation, 12, 177.

Siggaard Andersen, O., Engel, K., Jorgensen, K., and Astrup, P. (1960) Scandinavian fournal of Clinical and Laboratory Investigation, 12, 172 .

Vallbona, C., Pevny, E., and McMath, F. (1971). Computers and Biomedical Research, 4, 623 .

\section{Specificity of Serum Creatine Kinase Isoenzymes in Diagnosis of Acute Myocardial Infarction}

\section{A. KONTTINEN, H. SOMER}

British Medical fournal, 1973, 1, 386-389

\section{Summary}

A study of the diagnostic value of serum creatine kinase (CK) isoenzymes showed that MB isoenzyme, which characterizes heart tissue, was a specific and sensitive indicator of acute myocardial infarction. In cases where the clinical picture was complicated by ventricular tachycardia, severe congestive failure, shock, or resuscitation procedures heart, liver, and muscle enzymes were increased. There was also an increase in lactate dehydrogenase isoenzyme values in these cases; indeed, the only enzyme test that correlated well with electrocardiographic and necropsy findings was the MB isoenzyme.

\section{Introduction}

Serum creatine kinase (CK) measurement is established as a sensitive indicator of acute myocardial infarction. Serum CK activity is raised, however, in muslce diseases (Pearce et al., 1964), brain damage (Dubo et al., 1967), alcoholism (Konttinen et al., 1970), and sometimes in pulmonary embolism (Perkoff, 1968) or after electroconversion of heart rhythm (Konttinen et al., 1969). The specificity may be expected to be improved by serum CK isoenzyme determinations, since the $\mathrm{MB}$ isoenzyme of $\mathrm{CK}$ is found almost exclusively in the myocardium (Van der Veen and Willebrands, 1966).

The first approach to evaluate the contribution of the myocardium to the serum $\mathrm{CK}$ isoenzymes was made recently in selected patients with proved uncomplicated transmural infarctions (Konttinen, and Somer 1972). The patients were selected in order to avoid the possible extracardiac release of CK isoenzymes into the serum. The present study was undertaken to evaluate the specificity and sensitivity of serum CK isoenzymes, determined with our improved method (Somer and Konttinen, 1972b), in comparison with other enzyme tests on 61 unselected patients admitted to hospital for substernal pain suggestive of myocardial infarction.

First Department of Medicine, University Central Hospital, Helsinki, and Wihuri Research Institute, Helsinki, Finland

A. KONTTINEN, M.D., Assistant Chief Physician and Senior Lecturer in Medicine

H. SOMER, M.D., Research Fellow

\section{Patients and Methods}

The 61 patients were admitted to hospital within 48 hours after an attack suggestive of coronary disease. Bedside examinations were made during the first two hospital days, with special attention to the appearance of atrial and ventricular gallops, paradoxical pulse, and mitral insufficiency, all of which are observable in most cases of acute myocardial infarction (Heikkilä et al., 1971). Besides the conventional 12-lead E.C.G., body temperature, leukocyte count, and sedimentation rate were measured.

Myocardial infarction was regarded as proved by the appearance of $Q R S$ complexes or a $Q$ wave exceeding $0.04 \mathrm{sec}$, and having a depth of at least one-fourth of the corresponding $R$ wave and, in patients with mainly posterior infarcts according to Perloff (1964), where subendocardial extension reached the inferoapical region (leads III and aVF or V5 and V6). At necropsy in one of these patients an acute infarct was found. Because some uncertainty always exists in cases of subendocardial infarction, indicated by coronary-type S-T and/or $T$ changes, this group was considered separately. The total series was divided into four groups.

Eighteen patients had an acute coronary attack with no evidence of myocardial infarction on the above-mentioned criteria.

Twenty-seven patients had acute proved myocardial infarction with no complications. Some, however, had slight left heart failure, as evidenced by rales in the lungs, but no pulmonary oedema. The infarcts were anteroseptal in 17 cases, inferior and/or inferoapical in 7, and mainly posterior and extending into the inferoapical region in 3.

Seven patients had acute subendocardial infarction, six anterior and one inferior.

Nine patients had suspected acute myocardial infarction with complications of an emergency character (see table II). Of these, six patients were in shock on admission for ventricular tachycardia or fibrillation, and in three the chest pain was accompanied by severe congestive heart failure. Five patients had E.C.G. evidence of an acute myocardial infarct, which was verified in one at necrosy. Despite the clinical picture four patients did not have E.C.G. evidence of acute infarction, and in one it was excluded at necropsy.

Analyses were made of the following enzymes from unhaemolysed sera taken during the first two hospital days, as reported earlier (Elliot and Wilkinson, 1961; Konttinen et al., 1969): lactate dehydrogenase (LD) and its isoenzymes, $\alpha$-hydroxybutyrate dehydrogenase (HBD), aspartate aminotransferase 